\title{
Molecular analysis and frequency of Staphylococcus aureus virulence genes isolated from bloodstream infections in a teaching hospital in Tianjin, China
}

\author{
L.X. Wang ${ }^{1}$, Z.D. Hu ${ }^{1}$, Y.M. Hu ${ }^{2}$, B. Tian ${ }^{1}$, Jing Li ${ }^{1}$, F.X. Wang ${ }^{1}$, H. Yang ${ }^{1}$, \\ H.R. Xu' ${ }^{1}$, Y.C. $\mathrm{Li}^{1}$ and J. $\mathrm{Li}^{1}$ \\ ${ }^{1}$ Department of Clinical Laboratory, General Hospital, \\ Tianjin Medical University, Tianjin, China \\ ${ }^{2}$ School of Medical Laboratory, Tianjin Medical University, Tianjin, China \\ Corresponding author: Z.D. Hu \\ E-mail: zhidonghu@yeah.net
}

Genet. Mol. Res. 12 (1): 646-654 (2013)

Received August 7, 2012

Accepted October 24, 2012

Published March 11, 2013

DOI http://dx.doi.org/10.4238/2013.March.11.12

\begin{abstract}
Staphylococcus aureus is an important cause of bloodstream infections worldwide. We examined the prevalence of genes that encode erythromycin ribosome methylase and bacterial toxins in S. aureus collected from bloodstream infections. Sixty different $S$. aureus isolates were obtained from blood cultures of patients who were admitted to a Teaching Hospital in Tianjin from January 2006 to August 2011. The susceptibility of the isolates to 16 antibiotics was tested. Methicillin-resistant $S$. aureus (MRSA) was identified using the disk diffusion method with cefoxitin. PCR was used to detect genes that encode the staphylococcal enterotoxins, Panton-Valentine leukocidin, toxic shock syndrome toxin 1 and erythromycin ribosome methylase. Molecular analysis of the MRSA strains was done using pulsed-field gel electrophoresis (PFGE) and staphylococcal cassette chromosome mec (SCCmec) typing. The positivity rates of mecA, ermA, ermB, and ermC in the isolates were $13 / 60,10 / 60,18 / 60$, and 18/60, respectively. Among the
\end{abstract}


60 isolates, 30 harbored enterotoxin genes, with sea as the most frequent toxin gene (33\%), followed by sec (15\%), sed $(12 \%)$, and seb $(5 \%)$. The see and tst genes were not found in any of the isolates. The $p v l$ gene was detected in four strains. Eleven MRSA isolates were of the SCCmec type III; two MRSA isolates could not be determined through SCCmec typing. PFGE analysis of the 13 MRSA isolates produced 8 distinct pulsotypes. Virulence genes and erythromycin ribosome methylase genes were highly prevalent in these isolates. The PFGE results demonstrated that the MRSA spread through cloning, mainly involving SCCmec type III.

Key words: Staphylococcus aureus; Bloodstream infections; Virulence gene; Erythromycin ribosome methylase gene

\section{INTRODUCTION}

Staphylococcus aureus is a leading cause of bloodstream infections (BSIs) worldwide (Malachowa et al., 2011). The 2008 Mohnarin Report from China showed that S. aureus $(729 / 10519,6.9 \%)$ is the 3rd most common cause of BSIs in China (Wang et al., 2010). In Italy and Brazil, $S$. aureus is also ranked as the most common cause of BSIs (Luzzaro et al., 2011; Marra et al., 2011). Methicillin-resistant S. aureus (MRSA) in particular has caused increasing concern in health systems throughout the world because of its high incidence and associated undesirable outcomes (Gasch et al., 2011).

The clinical importance of $S$. aureus is attributed to its high virulence and rapid development of drug resistance. $S$. aureus virulence factors include surface proteins, toxins, and enzymes (Arvidson and Tegmark, 2001). Thus far, studies on the virulence genes and epidemiology of $S$. aureus have been limited. Consequently, this study aimed to determine drug susceptibility patterns and identify the genes encoding staphylococcal enterotoxins (SEs) A to E, Panton-Valentine leukocidin (PVL), toxic shock syndrome toxin (TSST-1), and erythromycin ribosome methylase (ERM) in 60 S. aureus isolates from BSIs patients.

\section{MATERIAL AND METHODS}

\section{Bacterial isolates}

A total of 60 S. aureus samples were isolated from January 2006 to August 2011 in the General Hospital of Tianjin Medical University, a Tertiary Care Teaching Hospital with 1600 beds in China. These isolates were collected from the blood cultures of patients admitted into the General Intensive Care Unit, the Departments of Hematology and Nephropathy and other wards. All strains were identified using the VITEK-2 compact automatic system (Biomérieux, Marcy l'Étoile, France). The isolates were classified as MRSA based on their resistance to oxacillin, which was confirmed by testing for $m e c A$.

\section{Antibiotic susceptibility tests}

Antibiotic susceptibility test profiles for 16 antimicrobial agents (oxacillin, penicillin, gen- 
tamicin, ciprofloxacin, linezolid, clindamycin, erythromycin, rifampin, tetracycline, moxifloxacin, teicoplanin, tigecycline, trimethoprim-sulfamethoxazole, vancomycin, ampicillin-sulbactam, and levofloxacin) were determined using a VITEK-2 compact automatic system (Biomérieux). Susceptibility to cefoxitin was determined using a disk diffusion test. The standards for antimicrobial susceptibility testing and interpretation were based on Clinical and Laboratory Standards Institute standard M100-S20 (National Committee for Clinical Laboratory Standards, 2010), and tigecycline minimum inhibitory concentration (MIC) results were interpreted according to the breakpoints approved by the U.S. Food and Drug Administration (susceptible $\leq 0.5 \mu \mathrm{g} / \mathrm{mL}$ ). The $S$. aureus strain ATCC25923 was used as the quality control strain for the susceptibility test.

\section{Detection of $m e c A$ and virulence and ERM genes}

All isolates were cultured on blood agar and incubated overnight at $35^{\circ} \mathrm{C}$. DNA for polymerase chain reaction (PCR) was extracted as previously described (Wu et al., 2011) and immediately used for PCR or stored at $-20^{\circ} \mathrm{C}$. The presence of $m e c A$ was determined via PCR using a primer, as described elsewhere (Oliveira and de Lencastre, 2002). PCR amplifications were performed using a thermal cycler (Perkin Elmer, Waltham, USA) as follows: initial denaturation for $5 \mathrm{~min}$ at $94^{\circ} \mathrm{C}$; followed by 30 cycles of denaturation for $30 \mathrm{~s}$ at $94^{\circ} \mathrm{C}$, annealing for $30 \mathrm{~s}$ at $55^{\circ} \mathrm{C}$, and extension for $60 \mathrm{~s}$ at $72^{\circ} \mathrm{C}$, and a final extension for $7 \mathrm{~min}$ at $72^{\circ} \mathrm{C}$.

PCR amplification was performed for genes encoding the SEs SEA (sea), SEB (seb), SEC (sec), SED (sed), SEE (see), PVL (lukS-lukF), TSST-1 (tst), and ERM (ermA, ermB, ermC) as previously described (Johnson et al., 1991; Lina et al., 1999a,b; Cao et al., 2010). All PCR products were analyzed through agarose gel electrophoresis on 1.5\% agarose gels.

The PCR products were purified and then sequenced with BigDye terminator v3.1 using an ABI PRISM 3730XL DNA Analyzer (Applied Biosystems, Foster City, CA, USA). The DNA sequences obtained were compared with those in the National Center for Biotechnology Information database.

\section{Staphylococcal cassette chromosome mec (SCCmec) typing}

SCCmec typing and subtyping were performed as described previously (Zhang et al., 2005), and the amplification was performed in a GeneAmp PCR system 9700 system. PCR was conducted with an initial denaturation step at $94^{\circ} \mathrm{C}$ for 5 min followed by 10 cycles at $94^{\circ} \mathrm{C}$ for $45 \mathrm{~s}, 65^{\circ} \mathrm{C}$ for $45 \mathrm{~s}$, and $72^{\circ} \mathrm{C}$ for $1.5 \mathrm{~min}$. Afterward, another 25 cycles were conducted at $94^{\circ} \mathrm{C}$ for $45 \mathrm{~s}, 55^{\circ} \mathrm{C}$ for $45 \mathrm{~s}$, and $72^{\circ} \mathrm{C}$ for $1.5 \mathrm{~min}$, ending with a final extension at $72^{\circ} \mathrm{C}$ for $10 \mathrm{~min}$ and holding at $4^{\circ} \mathrm{C}$.

\section{Pulsed-field gel electrophoresis (PFGE)}

Molecular analysis of the MRSA strains was accomplished through PFGE. Genomic DNA was prepared on agarose plugs as previously described (Goering and Winters, 1992). The DNA was digested with $30 \mathrm{U}$ SmaI- (TaKaRa, Dalian, China) for $4 \mathrm{~h}$ at $30^{\circ} \mathrm{C}$. Contour-clamped homogenous electric field electrophoresis of the digested chromosomal DNA was performed on $1.0 \%$ pulsed-field certified agarose (BioRad, Hercules, CA, USA) at $6 \mathrm{~V} / \mathrm{cm}$ for $18 \mathrm{~h}$ at $14^{\circ} \mathrm{C}$ with pulse times of 4 to $40 \mathrm{~s}$, using a contour-clamped homogenous electric field DRIII system 
(BioRad). After electrophoresis, the gel was stained with $0.5 \mu \mathrm{g} / \mathrm{mL}$ ethidium bromide and photographed under ultraviolet illumination. The assessment and interpretation of the PFGE patterns were performed according to previously published criteria (Tenover et al., 1995).

\section{RESULTS}

\section{Antimicrobial susceptibility}

All S. aureus isolates were susceptible to teicoplanin, linezolid, tigecycline, and vancomycin. The majority of the isolates, that is, $55(91.7 \%)$ and $39(65.0 \%)$, were resistant to penicillin $\mathrm{G}$ and erythromycin, respectively. The resistance rates of $S$. aureus, MRSA, and methicillin-sensitive $S$. aureus (MSSA) are summarized in Figure 1. Up to 13 isolates were resistant to cefoxitin and harbored mecA (Figure 2A) (GenBank accession No. GU227428). Eleven (84.6\%) of the 13 MRSA isolates were multi-drug resistant (i.e., resistant to more than 3 classes of the non- $\beta$-lactam antibiotics tested).

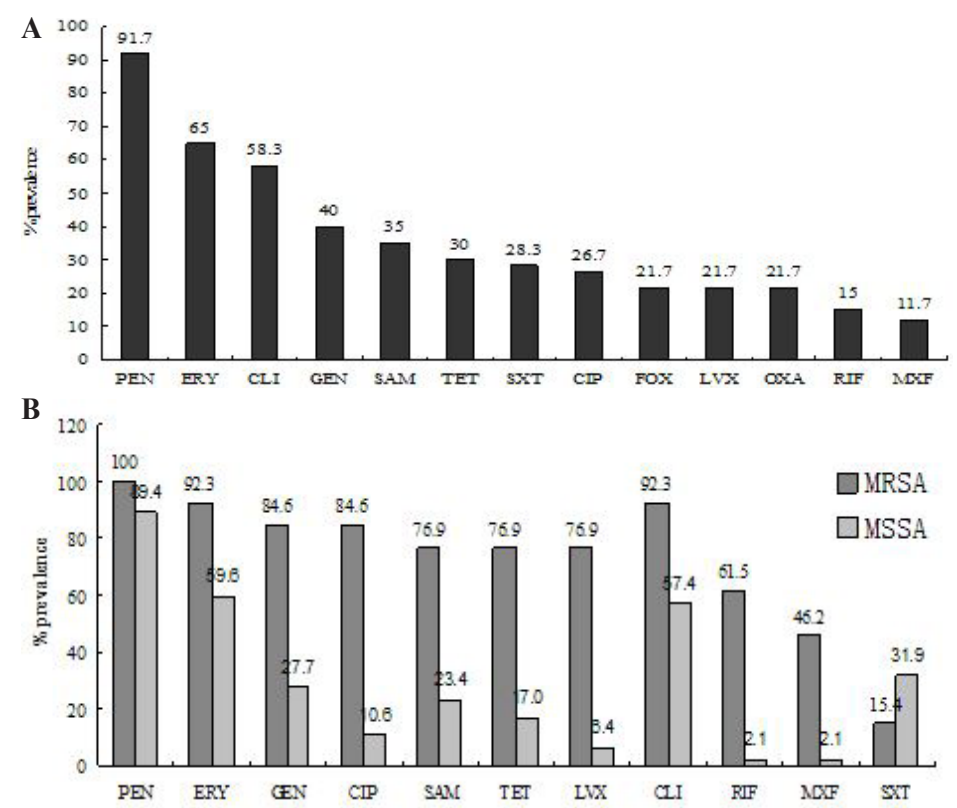

Figure 1. Antimicrobial resistance of Staphylococcus aureus isolates (A), antimicrobial resistance of methicillin-resistant $S$. aureus (MRSA) and methicillin-sensitive $S$. aureus (MSSA) isolates (B). PEN = penicillin; ERY = erythromycin; CLI = clindamycin; GEN = gentamicin; $\mathrm{SAM}=$ ampicillin-sulbactam; TET = tetracycline; $\mathrm{SXT}=$ trimethoprim-sulfamethoxazole; $\mathrm{CIP}=$ ciprofloxacin; FOX = cefoxitin; LVX = levofloxacin; OXA = oxacillin; RIF = rifampin; $\mathrm{MXF}=$ moxifloxacin.

\section{Distribution of virulence and ERM genes}

The distribution of genes that encode SE, PVL, and ERM is summarized in Table 1. In total, $30(50.0 \%)$ isolates were positive for SE genes (Figure 2B) (GenBank accession Nos. JN024684, AB479119, AB084256, and AY518388), 4 (6.7\%) were positive for $p v l$ (Figure 


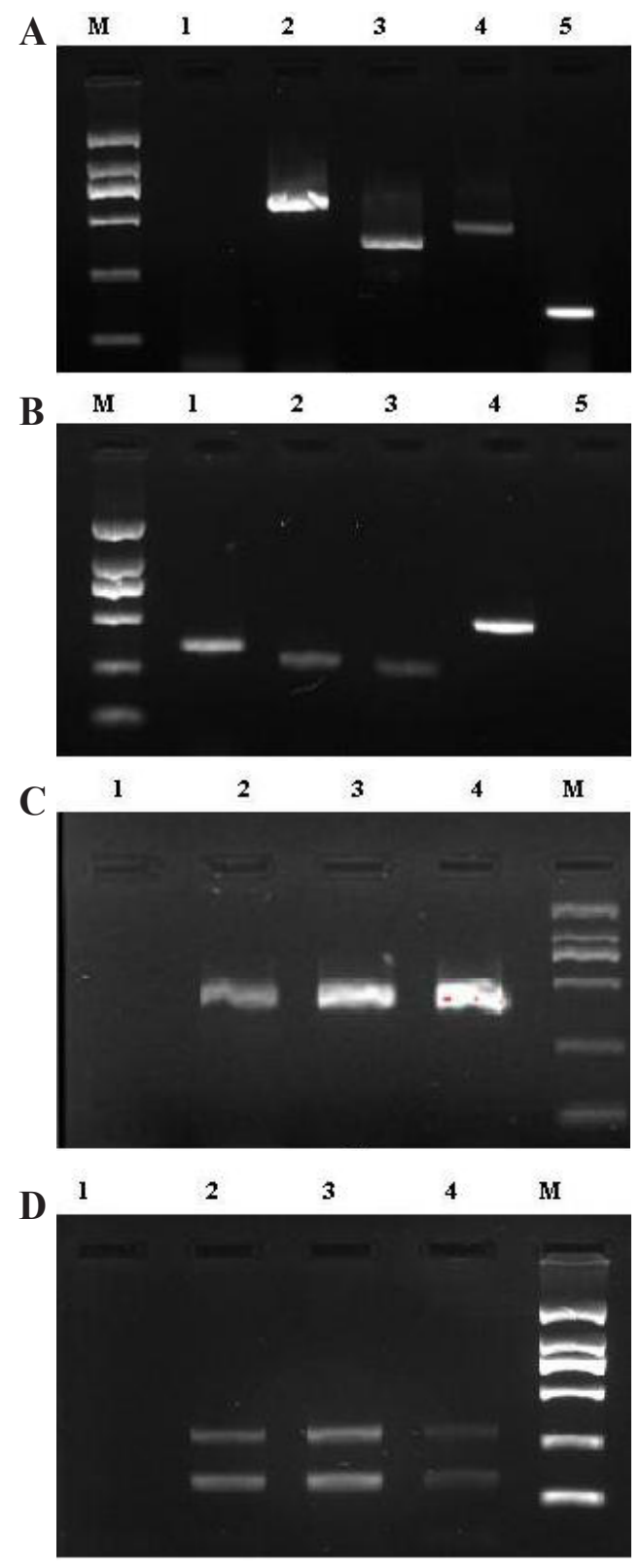

Figure 2. A. mecA and erm genes; B. staphylococcal enterotoxin (se) genes; C. Panton-Valentine leukocidin (PVL) genes, and D. SCCmec typing electrophorogram. A. Lane $1=$ negative control; lane $2=\operatorname{ermC}(572 \mathrm{bp})$-positive; lane $3=\operatorname{ermB}$ (359 bp)-positive; lane $4=\operatorname{ermA}$ (421 bp)-positive; lane $5=$ mecA (162 bp)-positive; lane $M$ $=$ DNA maker (up $\rightarrow$ down: $2000 \rightarrow 100 \mathrm{bp}$ ). B. Lane $1=$ sea $(341 \mathrm{bp})$-positive; lane $2=$ seb (285 bp)-positive; lane $3=\sec (257 \mathrm{bp})$-positive; lane $4=$ sed $(454 \mathrm{bp})$-positive; lane $5=$ negative control, lane $M=$ DNA maker (up $\rightarrow$ down: $2000 \rightarrow 100$ bp). C. Lane $1=$ negative control; lanes 2 to $4=$ PVL (433 bp)-positive; lane $M=$ DNA maker (up $\rightarrow$ down: $2000 \rightarrow 100 \mathrm{bp}$ ). D. Lane $1=$ negative control; lanes 2 to $4=$ SCCmec III $(280$, 147 bp)-positive; lane $M=$ DNA maker (up $\rightarrow$ down: $2000 \rightarrow 100$ bp). 
2C) (GenBank accession No. AB532026), and 39, including all MRSA isolates, were positive for erm (see Figure 2A) (GenBank accession Nos. AF466413, HQ683763, Y17294). The gene that encodes SEA was the most common SE gene and was detected in 20 isolates. A total of 21 isolates contained single SE genes and 9 carried 2 SE genes; see and tst were negative in all strains. Four isolates that harbored $p v l$ were MSSA, and $p v l$ was not detected among the 13 MRSA isolates. Approximately 65.0\% (39/60) of these isolates harbored ERM genes, with ermB and erm $C$ being the most common (30.0\%).

Table 1. Distribution of virulence genes and erythromycin ribosome methylase genes in 60 Staphylococcus aureus isolated from bloodstream infections.

\begin{tabular}{lrcccccrr}
\hline & \multicolumn{6}{c}{ Number (\%) of isolates positive for virulence genes and erythromycin ribosome methylase genes } \\
\cline { 2 - 8 } & \multicolumn{1}{c}{ sea } & seb & sec & sed & lukS-lukF & erma & ermb & ermc \\
\hline MRSA (13) & $11(84.6)$ & ND & ND & ND & ND & $10(76.9)$ & ND & $9(69.2)$ \\
MSSA (47) & $9(19.1)$ & $3(6.4)$ & $9(19.1)$ & $7(14.9)$ & $4(8.5)$ & ND & $18(38.3)$ & $9(19.1)$ \\
Total (60) & $20(33.3)$ & $3(5.0)$ & $9(15.0)$ & $7(11.7)$ & $4(6.7)$ & $10(16.7)$ & $18(30.0)$ & $18(30.0)$ \\
\hline
\end{tabular}

$s e=$ genes for staphylococcal enterotoxins; $l u k S-l u k F=$ genes for Paton-Valentine leukocidin; erm = genes for erythromycin ribosome methylase; MRSA and MSSA = methicillin-resistant and -sensitive $S$. aureus, respectively; $\mathrm{ND}=$ not detected.

\section{Molecular typing of MRSA isolates}

SCCmec typing results showed that $11(11 / 13,84.6 \%)$ MRSA isolates were SCCmec type III (Figure 2D); however, typing in 2 MRSA isolates were undeterminable. Analysis of the 13 MRSA isolates produced 8 distinct pulsotypes designated A-H (Figure 3). The PFGE pattern types were as follows: type $\mathrm{A}$ ( 2 isolates), type $\mathrm{B}$ ( 2 isolates), type $\mathrm{C}$ ( 2 isolates), type $\mathrm{D}$ (1 isolate), type $\mathrm{D} 1$ (1 isolate), type $\mathrm{E}$ (2 isolates), type $\mathrm{F}$ (1 isolate), type $\mathrm{G}$ (1 isolate), and type $\mathrm{H}$ (1 isolate). No pattern predominated among the isolates, which were collected from patients in the General Intensive Care Unit, the Cadre Ward and Departments of Hematology, Nephropathy, Rehabilitation Medicine, and Chinese and Western medicine.

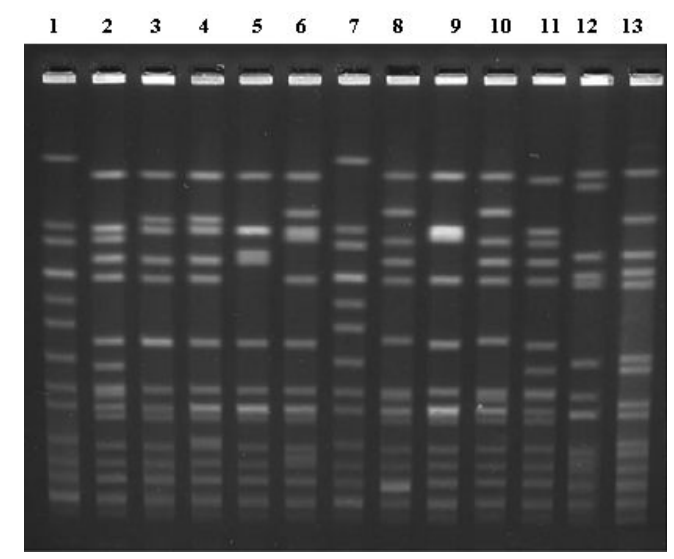

Figure 3. Pulsed-field gel electrophoresis of 13 methicillin-resistant Staphylococcus aureus from bloodstream infections. Lanes 1 and $7=$ pulsed-field gel electrophoresis (PFGE) type A; lanes 2 and $11=$ PFGE type B; lanes 3 and $4=$ PFGE type $\mathrm{C}$; lane $6=\mathrm{PFGE}$ type $\mathrm{D}$; lane $9=\mathrm{PFGE}$ type $\mathrm{D} 1$; lanes 8 and $10=\mathrm{PFGE}$ type $\mathrm{E}$; lane $5=$ PFGE type F; lane 12 = PFGE typeG; lane 13 = PFGE type $\mathrm{H}$. 


\section{DISCUSSION}

S. aureus is the causal pathogen of a wide range of infectious diseases ranging from skin and soft tissue infections to toxin-mediated diseases such as pneumonia and bacteremia (Holtfreter et al., 2007), many of which are caused by MRSA (Hesje et al., 2011). MRSA dissemination has become an important challenge at hospitals in all geographic areas owing to the emergence of isolates resistant to various antibiotic groups (Gomes et al., 2006). MRSA is a common cause of BSIs, which are often associated with invasive infections and high mortality rates (Moore et al., 2011). In this study, the antimicrobial susceptibility profile and distribution of the virulence and ERM genes of $60 \mathrm{~S}$. aureus samples isolated from BSIs were determined. In addition, the molecular typing data for 13 MRSA strains were reported.

All of the isolates were susceptible to tigecycline, vancomycin, and linezolid. The resistance rates of the 60 isolates to penicillin and erythromycin exceeded 91.7 and $65.0 \%$, respectively. In addition, all MRSA isolates were resistant to oxacillin and cefoxitin, which agrees with the results of previous experiments (Scazzocchio et al., 2011). Our data showed that the resistance rate of MRSA was higher than that of MSSA except with trimethoprimsulfamethoxazole. Vancomycin has remained the mainstay therapy for serious Gram-positive infections, particularly MRSA BSIs; however, therapeutic failure with vancomycin is increasingly reported (Charles et al., 2004; Moore et al., 2011). During recent years, an increase in vancomycin MICs against $S$. aureus has been observed worldwide (Taj et al., 2010; Moore et al., 2012). Increased mortality, treatment failure, and length of hospital stay have been reported in patients treated with vancomycin for MRSA bacteremia when isolates have a vancomycin MIC of $>1 \mu \mathrm{g} / \mathrm{mL}$ (Lubin et al., 2011). No vancomycin-resistant $S$. aureus isolates were detected in this study; however, $10 \mathrm{~S}$. aureus isolates exhibited a vancomycin MIC of $>1 \mu \mathrm{g} /$ $\mathrm{mL}$, which is often associated with treatment failure (Lubin et al., 2011). A recent study has revealed that daptomycin is associated with better outcomes than vancomycin for the treatment of BSIs caused by MRSA with higher vancomycin MICs, suggesting that switching to alternative agents may be an effective treatment strategy when the isolate has a high vancomycin MIC or when patients are not improving under conventional therapy ( Moore et al., 2012).

The current study analyzed the genes that encode SE, PVL, and ERM. The results showed that the virulence gene profiles of $60 \mathrm{~S}$. aureus isolates varied remarkably. Up to $84.6 \%$ of MRSA isolates harbored sea, whereas $19.1 \%$ of MSSA isolates harbored these genes. seb, $s e c$, and sed were not detected in MRSA isolates but were present in MSSA isolates. These results differ from those of previous studies (Kim et al., 2011; Ho et al., 2012). The PVL genes, which encode a pore-forming cytotoxin and cause tissue necrosis and leukocyte destruction, are frequently present in community associated-MRSA (Vandenesch et al., 2003; Lo et al., 2008; Hesje et al., 2011). The prevalence of PVL genes in $S$. aureus from various samples is diverse, with $79.5 \%$ of $S$. aureus from recurrent furunculosis and $2.63 \%$ from lower respiratory tract infections harboring PVL genes (Li et al., 2011; Garbacz et al., 2011). The surveillance of $p v l$ in $S$. aureus showed low occurrence. Only 4 MSSA strains were confirmed to have PVL genes $(6.7 \%, 4 / 60)$, which was consistent with results from previous reports (Shallcross et al., 2010; Năstase et al., 2010; Li et al., 2011; Ho et al., 2012).

Macrolide, lincosamide, and streptogramin antibiotics are widely used in the treatment of staphylococcal infections (Lina et al., 1999b). Resistance to erythromycin was detected in more than $60 \%$ of S. aureus and more than $80 \%$ of MRSA isolates. Approximately 39 
(100.0\%) isolates resistant to erythromycin carried ERM genes. In 13 MRSA isolates, ermA (found only in MRSA) and ermC were prevalent. ermB was detected only in MSSA, and the coexistence of ermA and erm $C$ was observed in 7 MRSA isolates.

Up to 11 MRSA isolates were SCCmec type III, whereas the typing of 2 isolates belonging to PFGE type A was indeterminable. The prevalence of SCCmec type III MRSA in this area is consistent with data in other reports (Chen et al., 2010). The 13 isolates belonged to 8 distinct PFGE patterns. In our hospital, the small-scale clonal spread of MRSA had been revealed between different wards or in one ward; however, no dominant isolates had been found.

S. aureus is one of the most frequent pathogens causing BSIs in China (Wang et al., 2010). The antimicrobial susceptibility profile and characteristics of virulence and ERM genes of BSI-causing $S$. aureus were explored in this study to enhance the current knowledge of these pathogens. Our results may ultimately help clinicians choose the most appropriate therapy for hospitalized patients.

\section{Conflict of interest}

The authors declare that they have no conflict of interest.

\section{REFERENCES}

Arvidson S and Tegmark K (2001). Regulation of virulence determinants in Staphylococcus aureus. Int. J. Med. Microbiol. 291: 159-170.

Cao H, Wang M, Li XP and Cao W (2010). Detection of enterotoxin gene in clinical S. aureus. Guangdong Med. J. 31: 2749-2752.

Charles PG, Ward PB, Johnson PD, Howden BP, et al. (2004). Clinical features associated with bacteremia due to heterogeneous vancomycin-intermediate Staphylococcus aureus. Clin. Infect. Dis. 38: 448-451.

Chen R, Shen DX, Yan ZQ and Wang H (2010). Genotyping on 47 Staphylococcus aureus strains associated with bloodstream infection. Zhonghua Liu Xing Bing Xue Za Zhi 31: 312-315.

Garbacz K, Piechowicz L, Baranska-Rybak W and Dabrowska-Szponar M (2011). Staphylococcus aureus isolated from patients with recurrent furunculosis carrying Panton-Valentine leukocidin genes represent agr specificity group IV. Eur. J. Dermatol. 21: 43-46.

Gasch O, Ayats J, Angeles DM, Tubau F, et al. (2011). Epidemiology of methicillin-resistant Staphylococcus aureus (MRSA) bloodstream infection: secular trends over 19 years at a university hospital. Medicine 90: 319-327.

Goering RV and Winters MA (1992). Rapid method for epidemiological evaluation of gram-positive cocci by field inversion gel electrophoresis. J. Clin. Microbiol. 30: 577-580.

Gomes AR, Westh H and de LH (2006). Origins and evolution of methicillin-resistant Staphylococcus aureus clonal lineages. Antimicrob. Agents Chemother. 50: 3237-3244.

Hesje CK, Sanfilippo CM, Haas W and Morris TW (2011). Molecular epidemiology of methicillin-resistant and methicillinsusceptible Staphylococcus aureus isolated from the eye. Curr. Eye Res. 36: 94-102.

Ho CM, Ho MW, Lee CY, Tien N, et al. (2012). Clonal spreading of methicillin-resistant SCCmec Staphylococcus aureus with specific spa and dru types in central Taiwan. Eur. J. Clin. Microbiol. Infect. Dis. 31: 499-504.

Holtfreter S, Grumann D, Schmudde M, Nguyen HT, et al. (2007). Clonal distribution of superantigen genes in clinical Staphylococcus aureus isolates. J. Clin. Microbiol. 45: 2669-2680.

Johnson WM, Tyler SD, Ewan EP, Ashton FE, et al. (1991). Detection of genes for enterotoxins, exfoliative toxins, and toxic shock syndrome toxin 1 in Staphylococcus aureus by the polymerase chain reaction. J. Clin. Microbiol. 29: 426-430.

Kim T, Yi J, Hong KH, Park JS, et al. (2011). Distribution of virulence genes in spa types of methicillin-resistant Staphylococcus aureus isolated from patients in intensive care units. Korean J. Lab. Med. 31: 30-36.

Li DZ, Chen YS, Yang JP, Zhang W, et al. (2011). Preliminary molecular epidemiology of the Staphylococcus aureus in lower respiratory tract infections: a multicenter study in China. Chin. Med. J. 124: 687-692.

Lina G, Piemont Y, Godail-Gamot F, Bes M, et al. (1999a). Involvement of Panton-Valentine leukocidin-producing Staphylococcus aureus in primary skin infections and pneumonia. Clin. Infect. Dis. 29: 1128-1132. 
Lina G, Quaglia A, Reverdy ME, Leclercq R, et al. (1999b). Distribution of genes encoding resistance to macrolides, lincosamides, and streptogramins among staphylococci. Antimicrob. Agents Chemother. 43: 1062-1066.

Lo WT, Lin WJ, Tseng MH, Wang SR, et al. (2008). Risk factors and molecular analysis of panton-valentine leukocidinpositive methicillin-resistant Staphylococcus aureus colonization in healthy children. Pediatr. Infect. Dis. J27: 713-718.

Lubin AS, Snydman DR, Ruthazer R, Bide P, et al. (2011). Predicting high vancomycin minimum inhibitory concentration in methicillin-resistant Staphylococcus aureus bloodstream infections. Clin. Infect. Dis. 52: 997-1002.

Luzzaro F, Ortisi G, Larosa M, Drago M, et al. (2011). Prevalence and epidemiology of microbial pathogens causing bloodstream infections: results of the OASIS multicenter study. Diagn. Microbiol. Infect. Dis. 69: 363-369.

Malachowa N, Whitney AR, Kobayashi SD, Sturdevant DE, et al. (2011). Global changes in Staphylococcus aureus gene expression in human blood. PLoS One 6: e18617.

Marra AR, Camargo LF, Pignatari AC, Sukiennik T, et al. (2011). Nosocomial bloodstream infections in Brazilian hospitals: analysis of 2,563 cases from a prospective nationwide surveillance study. J. Clin. Microbiol. 49: 1866-1871.

Moore CL, Lu M, Cheema F, Osaki-Kiyan P, et al. (2011). Prediction of failure in vancomycin-treated methicillinresistant Staphylococcus aureus bloodstream infection: a clinically useful risk stratification tool. Antimicrob. Agents Chemother. 55: 4581-4588.

Moore CL, Osaki-Kiyan P, Haque NZ, Perri MB, et al. (2012). Daptomycin versus vancomycin for bloodstream infections due to methicillin-resistant Staphylococcus aureus with a high vancomycin minimum inhibitory concentration: a case-control study. Clin. Infect. Dis. 54: 51-58.

Năstase E, Dorneanu O, Vremera T, Logigan C, et al. (2010). MecA and pvl genes detection in Staphylococcus aureus strains isolated from lower respiratory tract infections. Rev. Med. Chir. Soc. Med. Nat. Iasi 114: 1162-1168.

National Committee for Clinical Laboratory Standards (2010). Performance Standards for Antimicrobial Susceptibility Testing. Twentieth Informational Supplement, M100-S20. National Committee for Clinical Laboratory Standards, Wayne.

Oliveira DC and de Lencastre H (2002). Multiplex PCR strategy for rapid identification of structural types and variants of the mec element in methicillin-resistant Staphylococcus aureus. Antimicrob. Agents Chemother. 46: 2155-2161.

Scazzocchio F, Aquilanti L, Tabacchini C, Iebba V, et al. (2011). Microbiological and molecular characterization of nosocomial and community Staphylococcus aureus isolates. Epidemiol. Infect. 139: 613-622.

Shallcross LJ, Williams K, Hopkins S, Aldridge RW, et al. (2010). Panton-Valentine leukocidin associated staphylococcal disease: a cross-sectional study at a London hospital, England. Clin. Microbiol. Infect. 16: 1644-1648.

Taj Y, Abdullah FE and Kazmi SU (2010). Current pattern of antibiotic resistance in Staphylococcus aureus clinical isolates and the emergence of vancomycin resistance. J. Coll. Physicians Surg. Pak. 20: 728-732.

Tenover FC, Arbeit RD, Goering RV, Mickelsen PA, et al. (1995). Interpreting chromosomal DNA restriction patterns produced by pulsed-field gel electrophoresis: criteria for bacterial strain typing. J. Clin. Microbiol. 33: 2233-2239.

Vandenesch F, Naimi T, Enright MC, Lina G, et al. (2003). Community-acquired methicillin-resistant Staphylococcus aureus carrying Panton-Valentine leukocidin genes: worldwide emergence. Emerg. Infect. Dis. 9: 978-984.

Wang J, Liang J and Xiao YH (2010). Mohnarin of 2008: Bacterial Composing and Resistance in Bloodstream Infections. Chin. J. Nosocomiol. 20: 2399-2404.

Wu D, Li X, Yang Y, Zheng Y, et al. (2011). Superantigen gene profiles and presence of exfoliative toxin genes in communityacquired meticillin-resistant Staphylococcus aureus isolated from Chinese children. J. Med. Microbiol. 60: 35-45.

Zhang K, McClure JA, Elsayed S, Louie T, et al. (2005). Novel multiplex PCR assay for characterization and concomitant subtyping of staphylococcal cassette chromosome mec types I to V in methicillin-resistant Staphylococcus aureus. J. Clin. Microbiol. 43: 5026-5033. 